Doing Media History in a Digital Age

Change and Continuity in Historiographical Practices

Jensen, Helle Strandgaard

Published in:

Media, Culture \& Society

DOI:

$10.1177 / 0163443715607846$

Publication date:

2016

Document version

Peer reviewed version

Citation for published version (APA):

Jensen, H. S. (2016). Doing Media History in a Digital Age: Change and Continuity in Historiographical Practices . Media, Culture \& Society, 38(1), 119-128. https://doi.org/10.1177/0163443715607846 


\title{
Doing media history in a digital age: change and continuity in historiographical practices
}

\author{
Helle Strandgaard Jensen, University of Copenhagen, Denmark
}

Helle Strandgaard Jensen, University of Copenhagen, Karen Blixens vej 4, Copenhagen S 2300, Denmark. Email: rgx626\{at\}hum.ku.dk

Published online before print November 3, 2015, doi: 10.1177/0163443715607846 Media

Culture Society November 3, 20150163443715607846

\begin{abstract}
:
This article explores the challenges which digital media brings into the field of media history. It starts out by examining prominent television historians' understanding of digital archives as revolutionizing media historiography. These claims are examined by holding them up against texts that discuss wider issues in historiographical practices related to television history and transnational comparisons. This investigation is paired with my own experiences and the many methodological challenges I have encountered using digitalized sources for my new research. I end up concluding that digital archives in themselves make little difference to scholarly media history. In light of the lacking impact, I argue that we should study the cultural economy of these archives to better understand the corporate, political, and economical structures that govern their content and which also set the course for online digital processes that are active history-producing entities themselves.
\end{abstract}

Keywords:

archive digital media media history social memory television transnational

I took my first steps into the field of television history in 2006. This was the middle of a decade in which European broadcasting corporations began to share their audiovisual collections with the public via digital archives. For my first project, however, I never had the chance to use a digital archive as, in the end, nothing I wanted to see was digitalized.

Returning to the field almost a decade later, things seem to be quite different: the archives of several European broadcasting corporations can be accessed online, and we have the digital, online pan-European television archive 'EUscreen'. Institutionally, it seems there has been a massive effort to make audiovisual material available to the wider public in digital archives. Parallel to this process, blogs, wikis, and other sites with user-generated content are increasingly places where material for research projects can be found. In the process of looking for data, the wealth of written online material is only outshined by the abundance of clips on YouTube and similar sites. With these new contributions to media history, it looks like digital media has come to play a significant historiographical role. However, what appears to be an age where digitalization is revolutionizing media history, and an Internet connection is all one needs to collect data, is also a time that brings media historians face to face with new ethical and methodological problems. Investigating these problems on the basis of personal experience, this piece explores a set of challenges new digital media brings into media history. 
I have anchored the discussion of 'the digitalization of television history' to concrete experiences with digital media's impact on my own research. I did so because the challenges to established scholarly practices and grant ideas appeared in my dealings with everyday methodological problems: it was during the mundane collection of sources I discovered the discrepancy between what dominating scholars in the field of television history hail as the 'revolutionizing' forces of the new online collections, and these archives limited usability in actual scholarly research.

\section{The presumed impact of the online archive}

Leading scholars in the field of television history see the online archive as a game changer. Seemingly, there is almost no end to what we can achieve with the digitalized programs that are now available to us (De Leeuw, 2012; Ernst and Parikka, 2012; Noordegraaf, 2010; Verbruggen et al., 2014). For professional historians, it is only their conservatism that stands between them and the dawn of a new digital historicism, Andreas Fickers (2012) has argued. Fickers' argument echoes Roy Rosenzweig's (2008) claim: all historians today face a 'paradigm shift' due to digital media (see also Weller, 2013:1).

In 2012, Sonja De Leeuw hailed the online archive as 'the next stage in the cultural history of television' (De Leeuw, 2012: 5). With the digitalization and online availability of television history, she argued, we have moved away from traditional ways of doing television history since the digital availability of sources 'allows for a revisiting of television history, which until now has almost exclusively been known from institutional papers and records' (De Leeuw, 2012: 3).

Despite her optimism, De Leeuw also talks about problems with the television archive. The archives are, she says, 'incoherent and inconsistent', and there are problems with 'technical and metadata standards' (De Leeuw, 2012: 9) as well as 'the ontological character of the medium television ...' (De Leeuw, 2012: 11). However, she concludes by stating that 'the emergence of European television heritage online opens up the space for a truly transnational comparative approach to European television' (De Leeuw, 2012: 11). Here, we see how De Leeuw envisions media historians use the online archive, emphasizing scholarly agency in constructions of transnational and comparative television history.

Historians' agency in a new digital age is also the topic in a recent article by one of Europe's other agenda-setting media historians, Andreas Fickers. In Towards a New Digital Historicism? Doing History in the Age of Abundance, Fickers (2012) describes how historians have problems adapting to the new digital reality. He argues that what might be seen as a crisis of the systems that have traditionally been used to preserve the past is only a crisis in the eyes of historians because we cannot overcome our conservatism and 'quest for "scientific objectivity" based on the rigid methods of source criticism as developed by Ranke and his fellow companions in the 19th century' (Fickers, 2012: 24). The crisis is twofold according to Fickers. First, he argues that historians have difficulty coping with the ways in which digital archives (particularly, user-generated ones) bypass the regular systems used to preserve sources in traditional analogue archives (respect for the creator's systems, respect des fonds, and the original order, respect de l'ordre). Second, he argues that the change from scarcity to abundance in terms of sources available presents a challenge traditional historians have 
trouble comprehending. Hence, instead of coming up with what Fickers (2012) calls a 'New Digital Historicism' (p. 19), historians just ignore the problem.

In terms of television history, the abundance of sources that the Internet offers is particularly fruitful, Fickers argues. There is, however, one problem with using sources from YouTube and archives of a similar 'private-dependent' nature, he admits: the sources are not contextualized. He does, however, not suggest any practical solutions to this major problem except in passing. Fickers (2012) mentions how EUscreen is pioneering in this respect by "bringing together the technical experience for the development of semantic interoperability of the different meta-data [sic!] systems of archival collections, the [required] juridical knowledge ... the most important stakeholders ... and finally an academic network of European television historians as professional users. (p. 27)"

EUscreen, Fickers (2012) believes, is one way to tackle the consequences of how the 'computerization of our world has deeply affected all components of history as profession' ( $p$. 27). But is it computerization that has changed the historical profession, and has the historical profession really changed? The loss of the historian's privileged position is a recurrent theme in Fickers text, and it works almost as a self-explicatory argument for historians' ignorance of what the digital age might mean to them. Not all historians, however, fear the democratization of historiography. Instead of worrying about historians' conservatism, we might ask whether our lack of knowledge about the political and economical rationals that govern the online archive is not the real democratic problem.

\section{The impact of the online archive reexamined}

In An Ethic for a Politic of History in a Democratic Setting, historian Anette Warring (2013) discusses the consequences and significance the 'democratization of the production and usage of history' have for professional historians and their socio-cultural role (p. 47, my translation). To Warring, the democratization of history is a parallel process consisting of a great public interest in history and memory politics, which has meant an increasing number of agents involved in historiographical practices and an increasing interest among historians in popular memory. She argues that with the democratization of history, which she wholeheartedly welcomes, historians must take on a dual role that is both deconstructive and critical, but also engaging and constructive with regard to contemporary socio-cultural issues. This role requires a high level of transparency: we must make it easy for others to see our own interests in the histories we are writing, the reason and motivations for our engagement with the topics we choose, and the reasons why, and ways in which, we study them. In Warring's (2013) words, 'our dual role as professionals and fellow citizens, as well as our own use of history, must appear scientifically and normatively transparent' (p. 57). In light of Warring's insights, I believe we should revisit current claims about the revolutionizing factors of the online archives for media historians in the age of digital media.

Clarity and coherence on all levels of our research and subsequent civic engagement are the backbone of the transparency Warring calls for. Clearly formulated problem areas, research questions, and considerations of internal and external relevance must provide the foundation for the analytical framework in terms of theory, methodology, and selected data in an ethic for a politic of history. Creating transparency and fostering knowledge about the usage and 
construction of history are therefore what should be considered in terms of how historians fulfill their dual role in a democratic setting where digitalization processes have come to play a significant role in the construction of history.

With the principles for research transparency in mind, we could ask how exactly 'computerization' has fundamentally changed 'all components of history as profession' (Fickers, 2012: 8)? Formulating good research questions and making the case for their internal and external relevance have not changed in their basic form. We might find online the knowledge we use to formulate their internal relevance or the information we use to qualify their external relevance - but the process of coming up with a great idea and molding it into an interesting and researchable question remains the same in the digital age.

In the area of television history, 'researchability' might have changed when we look at the availability of online material, but this only counts if we look at a limited part of television history. According to John Corner (2003), there are five different aspects of television history that could be taken into account when engaging with 'television' as a historical object (pp. 275-276). Audiovisual material could function as a source for research into all these aspects but cannot stand alone - let alone make up the central body of sources. Thus, the archive, which provides the audiovisual sources, needs to provide much more than just these, and herein lies the problem with metadata, which both De Leeuw and Fickers acknowledge but do not follow to its logical end. If we do not know where the material we have found is from, who produced it, and what series of productions it was part of or anything else about its 'representative status' as a clip from a production in as series of 100 or 1000 of other programs, then how to do a systematic revision of its usability as a source? In the online archive, missing metadata is almost always the case and it takes away our possibility to systematically revise our sources and thereby also our potential to do transparent research. However, before we venture further into the questions of metadata, let us briefly consider the case of transparent 'research questions' and 'research design' in relation to transnational media history.

De Leeuw and Fickers both praise digitalization as something that fundamentally changed our possibilities for doing transnational history (De Leeuw, 2012; Fickers and Johnson, 2010). It is, of course, easier to gain access to sources from a computer than to travel to an archive or have sources brought to you through an interlibrary loan. But how to be sure that the sources needed are available online, so that, even if you have the language skills, you can do the research you find to be pertinent and relevant in the light of your dual role as historian? To answer this question, we need to understand what it takes to do transnational history.

Transnational history is a broad term that, in recent years, has come to signify comparative history and entangled history. This is also the case in television historiography (De Leeuw, 2012; Fickers and Johnson, 2010). Central to both approaches is the establishment of 'units' that are comparable or interact (Haupt and Kocka, 2009). The rather high level of methodology and theory involved in the design of transnational history demands much of the researcher: to say something about the causes of similarities or differences in comparative history studies or causes for breaks or continuity in entangled history studies demands precision in the establishment of hypotheses, the definition of analytical units, and the choice of sources. This is also why transnational history is often first written at the moment where 
national historiographies already exist (Bondebjerg, 2002: 62; Haupt and Kocka, 2009). There is nevertheless a problem with relying too much on the secondary literature in the study itself, because if one does not want to uncritically repeat the version a certain historiography is presenting on a certain problem or country, one has to immerse oneself thoroughly in the historiographical debates' (Kocka and Haupt, 2009: 13).

Pairing Corner's definition of television history with Kocka and Haupt's description of transnational history, we end up with a number of factors that must be taken into account when doing transnational television history. There is the need for a distinct and manifest contextualization of sources, a high level of clarity in the argument for a specific research design and engagement with the sources that do not only rely on how they are (rejrepresented in the secondary literature. In the following, I discuss the possibilities for living up to these standards using online archives.

My current research is about the transfer, appropriation, and demarcation of the American children's program, Sesame Street, in Europe during the 1970s. Sesame Street is an interesting case of transfer history because its complex history in Europe has the potential to become a truly transnational history of children's television. In the project, I ask why the program was received so differently in Europe and why it has such a big impact on the ways in which children's television was produced in the 1970s. I compare its transfer to and appropriation/demarcation in Italy, West Germany, East Germany, Britain, and Scandinavia and the pan-European discussions of the program at European Broadcasting Union (EBU) meetings.

The questions I have asked and my research design have only led to limited use of digitally available sources and digitally produced historiography. Traveling to archives and dusting off old newspapers and policy records, and searching for correspondence, budgets, and minutes from meetings far exceed the time I have been and will be spending looking at digitalized material available online and offline. This does not stem from my subscription to a particular kind of academic 'Rankeian' conservatism but from the fundamental problems I find in using the digital material currently available. These problems exist in the established, institutional national and international digital archives (offline and online), as well as the archives of a more loose and user-generated character such as YouTube and Archive.org.

\section{Producing digital histories in a decontextualized environment: the online archive}

When we talk about online television archives, it is useful to distinguish between two kinds of archives. One is the 'institutional archive' produced by a clearly identifiable institution and has a closed structure for uploading, describing, and linking individual elements on the web page. This kind of archive includes digital archives such as Danish Broadcasting Corporation's (DR) Bonanza, Swedish Television's (SVT) Öppet arkiv, or the pan-European EUscreen managed by the EUscreen Foundation. The material available in public online archives will often be a very small percentage of what is available offline. The other kind of archive is the open 'user-generated archive' such as Archive.org or YouTube. Here, uploading is not limited by institutional boundaries, and, therefore, the material available - including metadata depends on users. However, the overall structure of the archive is pre-determined by the host 
page. There are different problems (and possibilities) related to the two types of archives, but two of the key problems are the same: pre-selection and metadata.

In neither of the online archives do we know anything about how the material has been selected; we only know that it represents less than the tip of an iceberg. Nowhere in any of the digital archives I have seen online or worked with offline - neither the institutional nor the user-generated archives - have I been able to obtain any form of information about how the items displayed were selected. In terms of the user-generated archives, this might be expected: private individuals are quite likely simply to upload what they have without knowing from which corpus it has been selected or could be associated with. However, we might expect this to be different with large institutions, but it is not.

None of the online institutional archives available from European broadcasting services or the pan-European EUscreen contain information about the pre-selection process. The same accounts for DR and Radiotelevisione Italiana (RAI) where I had a chance to speak to librarians and curators; here, it seems possible that the digital offline archives contain all the digitalized material from their own analogue archives. This information does, however, not lead to knowledge of a systematic process of digitalization. We can only speculate about selection criteria. What further complicates the matter is that many programs were never kept even in their analogue format as budget restrictions made producers re-use raw tape up until the 1970s and 1980s, and therefore, we do not know what was left to digitalize in the first place. The problem here is that with no knowledge of the pre-selection, we are left in the dark when it comes to doing critical source analysis in its most basic form (if we restrict our analysis to online archives). We cannot determine how a source fits into our analysis, if we do not know how it is related to other sources in our corpus, and we cannot find out, if we do not know whether the individual clips we see express a general or an exceptional way of creating television at a particular time.

The case of DR's Bonanza archives' display of children's television in the past shows how important knowledge about the process of pre-selection is. In Bonanza, it is almost exclusively only one of the two dominant ways of doing children's television in the 1970s that is displayed (http://www.dr.dk/Bonanza/kategori/Boern.htm; accessed 27 July 2014). Bonanza's 'children's' category has clips and programs that are primarily fictional and emphasize entertainment elements. Hardcore social realism and more educational television are hard to find, although this type of television was widely produced and very influential during this period (Jensen, 2013). I would never have discovered what was missing in this archive by merely looking at what is displayed online. Nor would I have found out by looking at DR's much, much bigger offline archive since information about the pre-selection process is missing here, too. In order to write a history of Danish children's television and the influence of '1968', sources need to be found elsewhere (e.g. policy papers at the national archives, program reviews in newspapers and magazines, and, importantly, TV schedules for the years in question). These problems apply to all the institutional online and offline archives of which I have knowledge, and it clearly exposes the strict limitations for using digitalized audiovisual material on its own.

The digital television archive is, of course, a construction, a history-producing entity in itself, just like any other archive. This has also been pointed out in many other recent studies 
(Hagedoorn, 2013; Noordegraaf, 2010; Pajala, 2010), but although they focus on the sociocultural construction of knowledge within the archive, they do not address the pre-selection process as a central theme. Mari Pajala's (2010) research focuses on archives hosted in Sweden, Britain, Finland, Ireland, and Spain and the social construction of memory. She analyses the display of the elements within the archive, not why these elements were chosen in the first place. Julie Noordegraaf's (2010) work also favors the social construction of knowledge in the digital television archives while the question of pre-selection is only mentioned in passing. However, without knowledge of the selection process and with only very limited knowledge of the sources' link to any of the contexts in which they could be interpreted (metadata), the digital audiovisual archives cannot form the basis for transparent and thorough research on their own, let alone become the foundation for a 'new digital historicism'. The limited potential, which the digital archive holds to professional historians on its own, is evident if we go back to Corner's definition of television history and Warring's definition of the historian's dual role.

In Corner's definition of television history, audiovisual material cannot stand alone, and Warring pointed to the necessity for a transparent research process. In historical research, transparency relates to doing source criticism based on knowledge of the archive's respect des fonds and its respect de l'ordre. Even in an archive such as EUscreen in which some kind of contextualization has been provided for (a limited number of) the available clips, this archive alone does not present a revolution in (transnational) television history. The lack of knowledge about the pre-selection of the clips makes it impossible to know what one would be comparing and to establish reliable 'units of comparison' even if it were possible to find clips related to the same topic/genre/era from different countries/channels. We can only create a transparent research process when supplying the audiovisual material with forms of knowledge that allows for systematical revision of the available material.

In some ways the digital archive is useful, of course, for instance, when we have established the context of a program through the use of other sources and actually can see what it looked like. I am currently working with documents from the Children's Television Workshop (CTW) about Sesame Street, and although this archive is overwhelming in terms of size, metadata registration, and availability, the printed sources give limited insight into the programs themselves. I can read many details about how CTW wanted to produce a particular program - for instance, about the letter ' $F$ '. I know all about the production's technical details, who the producers were and what they thought about children's needs, wishes, and capabilities; I might even be able to get hold of an entire script. But what were the colors used, the tone of voice, the gestures, the clipping, framing, and so on? All of these, which are important for determining the 'inscribed' child viewer, can be added to my analysis only if I see the show. With Sesame Street, I am actually very lucky in terms of existing clips and metadata. With many other programs, it is not the case. In that sense, the digital archive will make a difference to my work, but the work itself could never be done with the digital sources and their metadata alone.

The problems one encounters doing research related to the RAI clearly underline why digital sources and their metadata alone cannot at present be the starting point for a revolutionizing turn in television historiography. RAI has a relatively large digital archive, which is available to registered visitors in one of the corporation's public libraries. When I came to the library, I 
was initially interested to know when and why RAI had bought Sesame Street, how it was broadcast, and how it related to some of the other children's shows of the period. I was very surprised to learn that RAI only had a digital archive with audiovisual material. This archive was vast but of limited use because of its vague pre-selection procedure. I found some clips from Sesamo Apriti (Sesame Street's Italian title) from 1978 and 1979 but with limited metadata (often, airdate only). Even if all I wanted to know was whether 1978 was the first year RAI broadcast Sesamo Apriti, I have no chance of finding an answer in the digital archive. 'Where are the printed sources, your policy papers, internal reports and the like?', I asked. 'In the national archives?' 'No, there is no archive' was the horrifying answer. The only archives available to anybody besides the RAI administration are the collections in the national archives from the period during Fascism! In the end, I was able to obtain two policy documents from 1969; but, alas, nobody could tell me where they came from, why they existed, and who had produced them - even the librarians were surprised that they had ended up on my desk and wanted a copy for the internal library. My problem with these two documents, of course, was the same as with all the digitalized audiovisual material available: I could not establish their context from the way in which they were presented to me. My experiences at the RAI - where a vast collection of digitalized audiovisual material is available, but fundamental printed sources are missing - show that digitalization does not bring about a revolution in (professional) television historiography.

\section{Conclusion and the road ahead}

New histories of television are brought about by the questions we ask and the way we answer them. Digital television archives alone do not allow us to answer questions in a way that is transparent (i.e. based on source criticism), due to the lack of knowledge about the preselection process and limited metadata. The transparency that Warring sees as the foundation for the historian's dual role in a democratic society is not reachable if we only use sources from the digital television archives that exist today. Furthermore, transnational history's basic principle, to construct clearly identifiable units for comparison (or an understanding of the transfer process), is also violated by the decontextualized manner in which the archives display their material. We cannot establish our units for the analysis solely from the audiovisual material available digitally, let alone engage critically with existing (national) historiographies.

From this conclusion, I believe the road ahead for media historians is to turn to the cultural economy (Du Gay, 1997) of digital archives. This involves investigating the economy and politics of pre-selection for digitalization and online display among broadcasting corporations. We need to gain insight into the logics of what material they display online and thus how images of the past are constructed in the light of corporate interests. Because, even if others have pointed to the construction of knowledge in the digital archive, they have been focused on the social and cultural processes of knowledge construction rather than the political, economical, or technical processes behind media corporations' digitalization processes (one exception being Barra and Scaglioni, 2012). Having knowledge about the cultural economy that influences the construction and content of digital archives will, hopefully, in time make these archives easier to use in a systematic and transparent scholarly historiography. This would also help media historians bridge the gap between scholarly 
research and social memory because it prioritizes the governing of overlapping material from these two domains.

A cultural economy approach to digital archives would help us turn to studying these as creators of popular memory motivated by other factors than cultural and social values. This would relate them to the new forms of media historiography allowed by digital media and its room for "'alternative" social memories and remembering practices' (Keightley and Schlesinger, 2014: 747). Drawing upon Niels Brügger and Niels Ole Finnemann's (2013:66) conceptualization of digital media, media historians could relate their professional endeavors to the 'archive of contemporary life', thereby making us understand the digital archive as 'historical actor' (Robertson 2011:1). One way of addressing questions of pre-selection and memory making in a cultural economy context could be turning to investigations that combine organizational memory studies and social remembering as suggested by Rowlinson et al. (2010). Their suggestions will help to focus on organizational conditions and structures in memory construction, thereby addressing the digital archive's role in memory-making in other ways than as an outcome of a cultural process. Focus on corporations will also help researchers to address the 'methodological nationalism' the works on television archives and memory culture, and the archives themselves, often end up in.

\section{Article Notes}

Funding DFF-MOBILEX Mobility grants financed by the Danish Council for Independent Research and FP7 Marie Curie Actions - COFUND, grant id: DFF-1321-00024. Project title: Shaping childhood through television. The transfer and demarcation of Sesame Street in 1970s Europe.

\section{References}

Barra L, Scaglioni M (2012) Making the most of the archive: commercial exploration of the digital archive in contemporary Italian Network TV. View 1(1): 40-47.

Bondebjerg I (2002) Scandinavian media histories - a comparative study. Institutions, genres and culture in a national and global perspective. Nordicom Review 23(1-2): 61-79.

Corner J (2003) Finding data, reading patterns, telling stories: issues in the historiography of television. Media, Culture \& Society 25(2): 273-280.

De Leeuw S (2012) European television history online: history and challenges. View 1(1): 311.

Ernst W, Parikka J (2012) Digital Memory and the Archive. Minneapolis, MN: University of Minnesota Press.

Fickers A (2012) Towards a new digital historicism? Doing history in the age of abundance. View 1(1): 19-26. 
Fickers A, Johnson C (2010) Transnational television history: a comparative approach: introduction. Media History 16(1): 1-11.

Finnemann NO, Brügger N (2013) The Web and Digital Humanities: Theoretical and Methodological Concerns. Journal of Broadcasting and Electronic Media 57(1): 66-80.

du Gay P (ed) (1997) Production of Culture/Cultures of Production. London: SAGE/Open University Press.

Hagedoorn B (2013) Television as a hybrid repertoire of memory. View 2(3): 52-64.

Haupt HG, Kocka J (eds) (2009) Comparative and Transnational History: Central European Approaches and New Perspectives. New York: Berghahn Books.

Jensen HS (2013) TV as children's spokesman: conflicting notions of children and childhood in Danish children's television around 1968. Journal of the History of Childhood and Youth 6(1): 105-128.

Keightley E, Schlesinger P (2014) Digital media - social memory: remembering in digitally networked times. Media, Culture \& Society 36(6): 745-747.

Noordegraaf J (2010) Who knows television? Online access and the gatekeepers of knowledge. Critical Studies in Television 5(2): 1-19.

Pajala M (2010) Television as an archive of memories? Cultural memory and its limits on the Finnish public service broadcaster's online archive. Critical Studies in Television 5(2): 133145.

Robertson C (2011) Media History and the Archive. New York: Routledge.

Rosenzweig R (2008) Scarcity or abundance? Preserving the past in a digital era. American Historical Review 108(3): 735-762.

Rowlinson CB, Booth C, Clark P, et al . (2010) Social remembering and organizational memory. Organization Studies 31(1): 67-87.

Verbruggen E, Oomen J, Müller E (2014) Bringing Europe's audiovisual heritage online: eUscreenXL. IASA Journal 42: 54-60.

Warring A (2013) En demokratisk historiepolitisk etik [An ethic for a politic of history in a democratic setting]. Scandia 79(2): 47-58.

Weller T (2013) History in the Digital Age. London: Routledge 